\title{
High Strength Concrete Tests under Elevated Temperature
}

\author{
By Zhuoya $\mathrm{Wu}^{*}$, Sai Huen $\mathrm{Lo}^{\dagger}$, Kang Hai Tan ${ }^{*}$ \& \\ Kai Leung $\mathrm{Su}^{\star}$
}

In recent years, application of high strength concrete (HSC) has attracted increasing interest in the construction industry due to its significant economic, architectural, and structural advantages, compared to the conventional normal strength concrete (NSC). However, under fire condition, which is one of the most common hazards that attack building structures, HSC members may be subjected to explosive spalling. Strength reduction of structural members may occur, leading to severe consequences such as failure of members or even collapse of the whole structure. A newly designed 2layered cylindrical specimen consisting of an HSC core and an NSC outer layer is proposed to improve the fire performance of HSC members under elevated temperature. The NSC layer is designed to act as an outer layer insulation to reduce the thermal gradient and also serve as a lateral confinement to prevent the HSC core from spalling. Compression and thermal tests were performed on the specimens to investigate their strength and behavior under elevated temperature. Test results preliminarily verify the feasibility of 2-layered design and at the same time provide insights for the applicability of 2-layered columns in practical construction projects.

Keywords: 2-Layered Specimens, Elevated Temperature, High Strength Concrete, Normal Strength Concrete, Spalling.

\section{Introduction}

High strength concrete (HSC), as one of the most widely used construction materials, gains increasing popularity in the recent years due to the upsurge of high-rise buildings, long-span bridges and tunnels. Compared to the normal strength concrete (NSC), HSC has advantages in not only the structural but also the economic and aesthetic aspects. When applied in buildings, HSC is commonly used as structural members such as beams, columns and slabs, which function as the load bearing elements. It is therefore of particular importance to make sure that the high strength concrete members could survive from those extreme environmental conditions, among which fire has aroused primary concerns due to the spalling of HSC when exposed to elevated temperatures. Spalling refers to the breaking away of surface layers (pieces) of concrete from the structural elements exposed to high and rapidly rising temperatures, and the explosive spalling occurs in a more sudden and violent manner (Kodur 2000, Phan 2008). Though there is no one mechanism that can fully interpret this phenomenon, it

\footnotetext{
*PhD Student, The University of Hong Kong, China.

${ }^{\dagger}$ Professor, The University of Hong Kong, China.

*Professor, Nanyang Technological University, Singapore.

-Associate Professor, The University of Hong Kong, China.
} 
is believed by the majority that due to the high compactness (low porosity) of HSC, water vapor pressure trapped inside the concrete could induce spalling when the pore pressure gradually builds up and exceeds the tensile strength of concrete under elevated temperatures (Dwaikat and Kodur 2009, Phan 2002, Kodur et al. 2004, Ichikawa and England 2004, Ozawa et al. 2012, Kalifa et al. 2000, Mindeguia et al. 2010b).

Considering the fact that spalling usually occurs in depth of $10-50 \mathrm{~mm}$ from the concrete surface (Jeongwon et al. 2011), this study presents a newly designed 2-layered (2L) cylindrical specimen consisting of an HSC core and an NSC outer layer to mitigate the effect of spalling. The NSC layer is designed to act as an outer layer insulation to reduce the thermal gradient and also as a lateral confinement to prevent the HSC core from spalling. Although fiberreinforced HSC is one of the most commonly used method to mitigate spalling, drawbacks still exist. For concrete reinforced with polypropylene (PP) fiber, elastic modulus and compressive strength of the concrete are reduced (Wang et al. 2019, Jalasutram et al. 2017). For concrete reinforced with steel fiber, Zheng et al. (2018) pointed out the traditional mixing method could lead to the non-uniform distribution of steel fiber, mechanical properties of the concrete would therefore be affected. Chaichannawatik et al. (2018) found that the addition of fibers in the concrete would reduce the workability of the fiberreinforced concrete. On account of the lower workability, reduced compressive strength and difficulty of uniform mixing on site, it is necessary to implement the proposed 2-layered design.

\section{Literature Review}

Studies on the effects of high temperature on the mechanical properties of HSC could trace back to as early as the 1980s. Among these early studies were mostly material tests (Felicetti et al. 1996, Furumura et al. 1995, Sullivan and Sharshar 1992, Hammer 1995, Diederichs et al. 1988, Hertz 1992, Hertz 1984, Castillo and Durrani 1990) and element tests (Diederichs et al. 1995, Hansen and Jensen 1995, Sanjayan and Stocks 1993, Shirley et al. 1988). There were also some other early studies that adopted different techniques, for instance, the scanning electron microscopy and stiffness damage test to evaluate the properties and behavior of HSC at elevated temperatures (Lin et al. 1996, Nassif et al. 1995).

Castillo and Durrani (1990) investigated the compressive strength and loaddeformation relationship of HSC exposed to high temperature by conducting stressed and unstressed tests on cylinders made of high strength and normal strength concrete mixtures. Hertz (1984) and Hertz (1992) examined the effect of temperature, cylinder size and dosage of steel fibers on the compressive strength, elastic modulus and explosion behavior of silica-fume HSC and lightweight concrete. Diederichs et al. (1988) studied the material properties as well as the specimen shape and heating rate by performing unstressed tests, transient creep and relaxation tests on the specimens of three HSC with different mineral additions (blast furnace slag, silica fume and fly ash). Hammer (1995) 
observed a typical "breakpoint" at around $300^{\circ} \mathrm{C}$ in the strength-temperature curves, where an explosive failure may occur followed by the release of steam. Sullivan and Sharshar (1992) concluded that aggregate type could significantly affect the residual strength of concrete subjected to high temperature. Furumura et al. (1995) noted that in the unstressed tests there was a compressive strength recovery to ambient strength at $200^{\circ} \mathrm{C}$, which is not observed in the unstressed residual strength tests. Felicetti et al. (1996) performed unstressed residual strength tests on the HSC cylinder specimens and the test results revealed similar trends of reductions in compressive strength and elastic modulus as observed in other experimental studies mentioned above. Noumowe et al. (1996) conducted unstressed residual tests on NSC and HSC specimen. Results showed that both tensile strengths decreased similarly and almost linearly with increasing temperatures and NSC would become more porous than HSC as temperatures increased beyond $120^{\circ} \mathrm{C}$.

Three series of reinforced and prestressed concrete beam tests were performed in the research of Hansen and Jensen (1995), which showed that beams with fibers and protective coating were less suspected to spalling. Observations from the full scale T-beams fire tests by Sanjayan and Stocks (1993) reported HSC possesses a higher possibility of spalling in a fire than NSC and the drying rate of HSC is slower than NSC indicated by its higher moisture content. The report by Diederichs et al. (1995) summarized results from three column tests and indicated that the use of fibers to form capillary can help reduce the risk of spalling in HSC columns and also suggested that further researches may study the effects of various fiber contents. Shirley et al. (1988) conducted fire tests on HSC slab and concluded that the fire endurance of HSC and NSC had no significant difference and none of the specimens experienced any spalling or explosive behavior.

The one problem that early studies commonly address is the spalling or explosive behavior of HSC at elevated temperatures, though inconsistencies are also observed from the test results. While some researchers reported spalling phenomenon in HSC structural members, there were a few experimental studies showing little or no obvious spalling. Possible reason for this conflicting picture on the occurrence of spalling may attribute to the massive number of factors that affect spalling and their interdependency. To better understand the behavior and mechanism of HSC under elevated temperature, and to satisfy the fire safety requirements in practical construction projects, more recent researches has been done regarding the fire resistance of HSC.

\section{Mechanisms of Spalling}

The spalling pattern of HSC could be classified as minor, moderate and severe (explosive), according to the extent of spalled concrete. Spalling refers to the breaking away of surface layers (pieces) of concrete from the structural elements exposed to high and rapidly rising temperature, and the explosive spalling occurs in a more sudden and violent manner (Phan 2008, Kalifa et al. 2000, Phan and Carino 2002, Kodur 2000). In cases of severe spalling, it is 
very likely that the reinforcement would be directly exposed to heat, and therefore loss of load bearing capacity of structural members may occur, leading to severe consequences such as failure of members or even collapse of the whole structure. A review of literature shows that there are mainly three mechanisms that could account for the spalling phenomenon of HSC (Kodur 2000, Kodur et al. 2004, Jeongwon et al. 2011, Ozawa et al. 2012, Phan 2002).

\section{$\underline{\text { Thermal-Mechanical Spalling }}$}

When concrete is heated under fire, thermal stress develops due to restrained thermal expansion. When tensile stress reaches some critical values, vertical cracks will form between the concrete core and concrete cover (Gawin et al. 2003). If a driving force, such as axial compression, bending stress, or thermal expansion of concrete is applied, thermal-mechanical spalling happens. According to the studies conducted from the aspect of thermal stress, the critical factor influencing the thermal expansion is coarse aggregate (Jeongwon et al. 2011), and the presence of carbonate aggregate could help improve the fire endurance of HSC other than the siliceous aggregate (Kodur et al. 2003). In general, thermal-mechanical spalling occurs when the compressive strength of concrete is exceeded at the cover. A schematic diagram of thermalmechanical spalling of a concrete column is depicted in Figure 1.

Figure 1. Schematic Diagram of Thermal-Mechanical Spalling (Kodur 2000)

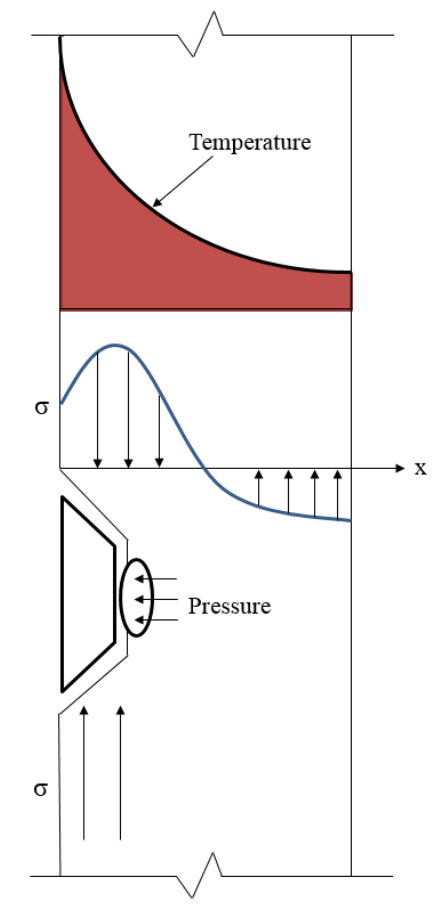

Thermal-Hydro Spalling

High strength concrete is made by lowering the water/cement ratio and 
adding some ultra-fine materials such as silica fume that can increases the strength of the cement-aggregate bond. Superplasticizers are also commonly added to the high strength mixes in order to compensate for the reduced workability. When concrete is heated under elevated temperature, liquid water inside the concrete will become vapor. Due to the low permeability (compact) nature of HSC, the vapor cannot escape the concrete, leading to the gradual build-up of pore pressure around the concrete surface. At $300^{\circ} \mathrm{C}$, the pore pressure could approximately reach $8 \mathrm{MPa}$ (Kodur 2000, Kodur et al. 2004). The tensile strength of concrete is much lower than its compressive strength, when concrete could not resist the induced pore pressure, spalling occurs. At the time of spalling, the pore pressure roughly equals to the saturated vapor pressure (SVP) (Mindeguia et al. 2010a, Kalifa et al. 2000). A schematic diagram of thermal-hydro spalling of a concrete column is depicted in Figure 2. It is reported by Hertz (2003) that low water content by weight (3-4\% or less) could reduce the possibility of spalling in concrete, a phenomenon that cannot be solely explained by the thermal-mechanical spalling theory, and is deemed to be mainly affected by the water vapor pressure (pore pressure). Thermal-hydro spalling, occurring at early stage of heating and with fierce spalling process, is therefore considered as the most critical spalling by the majority of researches, though it is still difficult to conclude an exact mechanism to fully interpret the phenomenon of fire induced spalling in HSC based on the state-of-the art (Khaliq and Kodur 2011, Khaliq and Kodur 2013, Phan and Carino 1998, Phan and Carino 2002, Jeongwon et al. 2011, Ozawa et al. 2012).

Figure 2. Schematic Diagram of Thermal-Hydro Spalling (Kodur 2000)

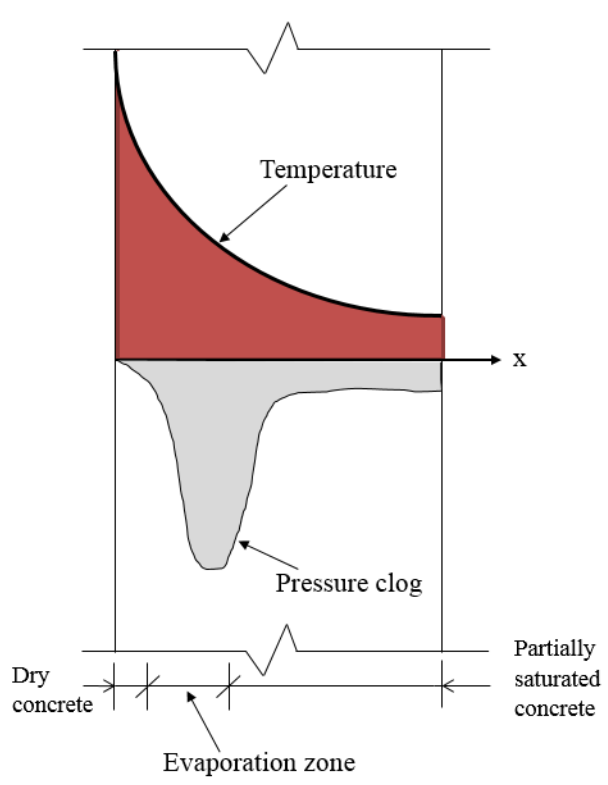

Water vapor pressure is closely connected to the heat or moisture transfer in concrete, which is strongly affected by the moisture conditions with concrete, and the effect is particularly strong in a high-temperature environment (Jeongwon et al. 2011). Measurement of heat/moisture transfer and pressure build-up is of 
great difficulties due to the restricted test conditions and the nature of the measured experimental process. However, development of new experimental methods accompanied by the progress in the test apparatus has promoted a few experimental and analytical studies on heat conduction, moisture transfer and pore pressure build-up (Kalifa et al. 2000, Zdeněk and Werapol 1979, Bažant et al. 1982, Ahmed and Hurst 1999, Phan 2008, Ichikawa and England 2004, Dwaikat and Kodur 2009, Phan 2002), though most of the pore pressures investigated are in one direction only. The experimental studies pay special attention to the data from the proximity of concrete surfaces reasoning the fact that spalling take place primarily in the range of 10-50mm depth from surface (Jeongwon et al. 2011).

\section{Thermal-Chemical Spalling}

Thermal chemical spalling consists of two types of spalling, namely, sloughing-off spalling at extremely high temperature and post cooling spalling after exposing to elevated temperature (Xing et al. 2011). The main cause of thermal-chemical spalling is the break-down of aggregate cement bond, such as calcium silicate hydroxide and calcium hydroxide (Schneider 1988). Since the threshold temperature of thermal-chemical spalling is relatively high at around $750^{\circ} \mathrm{C}$, it is considered to be the least critical among the three mentioned spalling. The temperature of thermal-chemical spalling is shown in Figure 3.

Figure 3. Temperature Range of Thermal-Mechanical Spalling



\section{Experimental Studies}

\section{Test Specimens}

Two identical groups, one for compression tests and the other for fire tests, of totally 12 cylindrical specimens are designed, within each group, three HSC and three $2 \mathrm{~L}$ specimens are prepared. No thermal couples are needed for the compression tests; therefore, thermal couples are only added in the group for fire tests, locating at middle height of all specimens. Thermal couples are placed in a perpendicular way as shown in Figure 4. The detailed dimensions of specimens can be found in Table 1 . The ratio between outer layer thickness and the outer diameter is 0.1 . 
Figure 4. Cylindrical Specimens for Experimental Tests

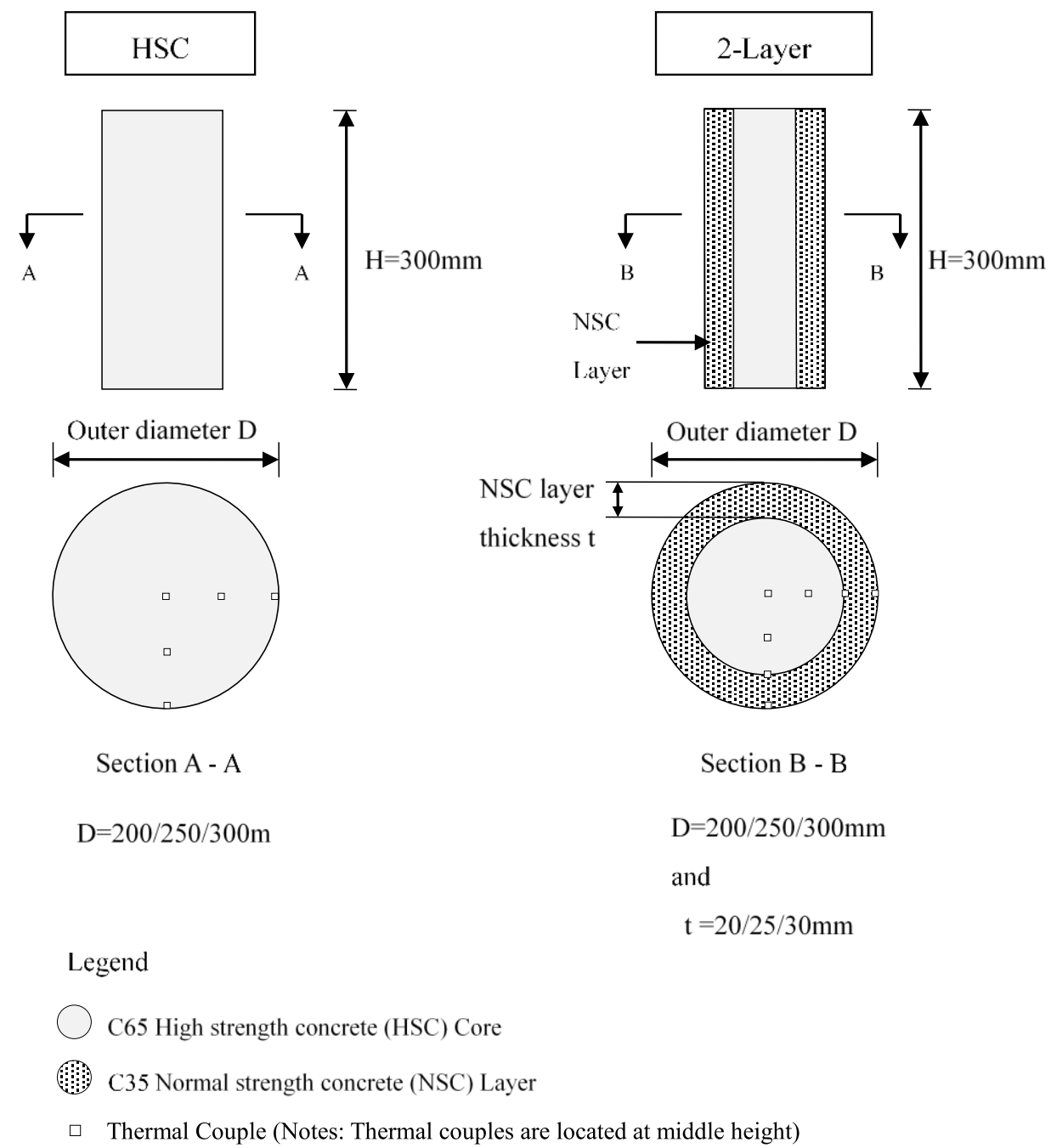

The casting of $2 \mathrm{~L}$ specimens have to be done twice: first the HSC core is cast, after one day, demold the HSC core and put it in a larger mold to cast the outer layer, as shown in Figure 5.

\section{Mix Proportions}

The mix proportions and compressive strength of C65 and C35 concrete could be referred to in Table 1. As shown in the table, the compressive strength of C65 concrete is only $50.7 \mathrm{MPa}$, which is much lower than the design strength. Since the concrete used in this test was mixed and cast manually, the low compressive strength is probably due to the poor workmanship such as insufficient mixing and inaccurate material weighing. Loading rate of $265 \mathrm{kN} / \mathrm{min}$ is adopted as recommended in British Standard. 
Figure 5. Casting of 2-Layer Specimens
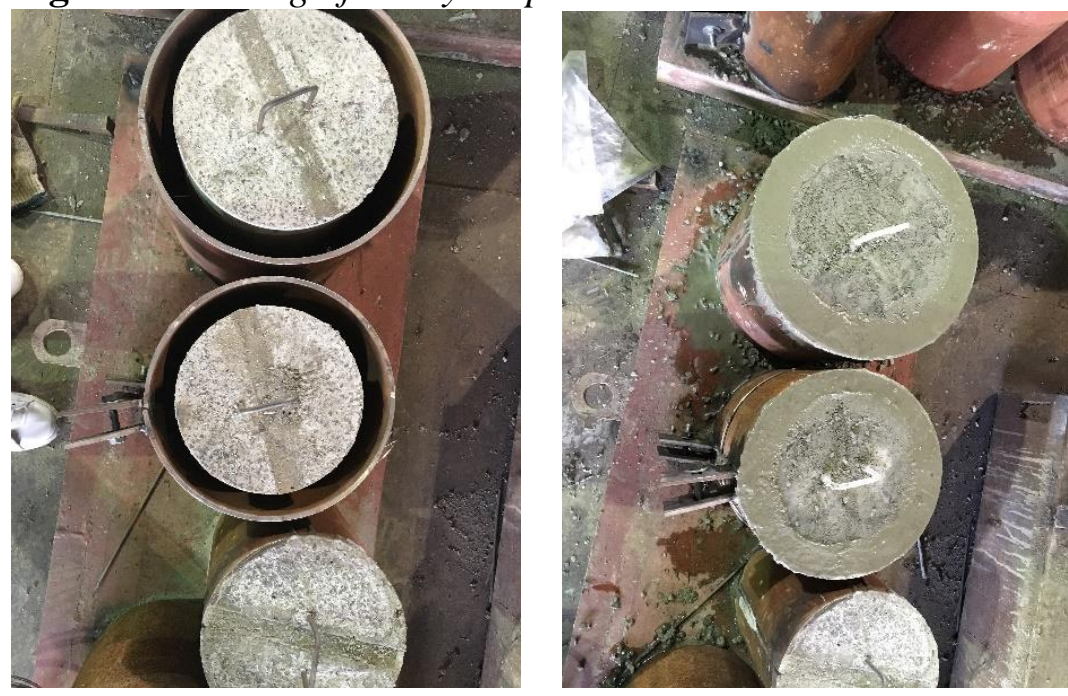

Table 1. Mix Proportions for C65 and C35 Concrete

\begin{tabular}{|c|c|c|c|c|c|c|}
\hline & $\begin{array}{c}\text { Cement } \\
\left(\mathrm{kg} / \mathrm{m}^{3}\right)\end{array}$ & $\begin{array}{c}\text { Water } \\
\left(\mathrm{kg} / \mathrm{m}^{3}\right)\end{array}$ & $\begin{array}{c}\text { Sand } \\
\left(\mathrm{kg} / \mathrm{m}^{3}\right)\end{array}$ & $\begin{array}{c}\text { Stone } \\
\left(\mathrm{kg} / \mathrm{m}^{3}\right)\end{array}$ & $\begin{array}{c}\mathrm{SP} \\
\left(\mathrm{kg} / \mathrm{m}^{3}\right)\end{array}$ & $\begin{array}{c}\text { Compressive } \\
\text { Strength } \\
(\mathrm{MPa})\end{array}$ \\
\hline C65 & 535 & 162 & 676 & 930 & 0.47 & 50.7 \\
\hline C35 & 350 & 168 & 720 & 1070 & $/$ & 32.9 \\
\hline
\end{tabular}

Heating Regime

The electrical furnace could be programmed to follow the ISO 834 standard temperature-time curve (Figure 6), which is represented by the equation:

$$
\mathrm{T}=345 \log 10(8 \mathrm{t}+1)+\mathrm{T}_{0}
$$

where $\mathrm{T}=$ furnace temperature $\left({ }^{\circ} \mathrm{C}\right) ; \mathrm{t}=$ time in minutes; and $\mathrm{T}_{0}=$ environmental temperature (taken as $20^{\circ} \mathrm{C}$ ). The highest temperature that can be achieved after the 4-hours' firing is $1150^{\circ} \mathrm{C}$ approximately. 
Figure 6. ISO 834 Standard Temperature-Time Curve

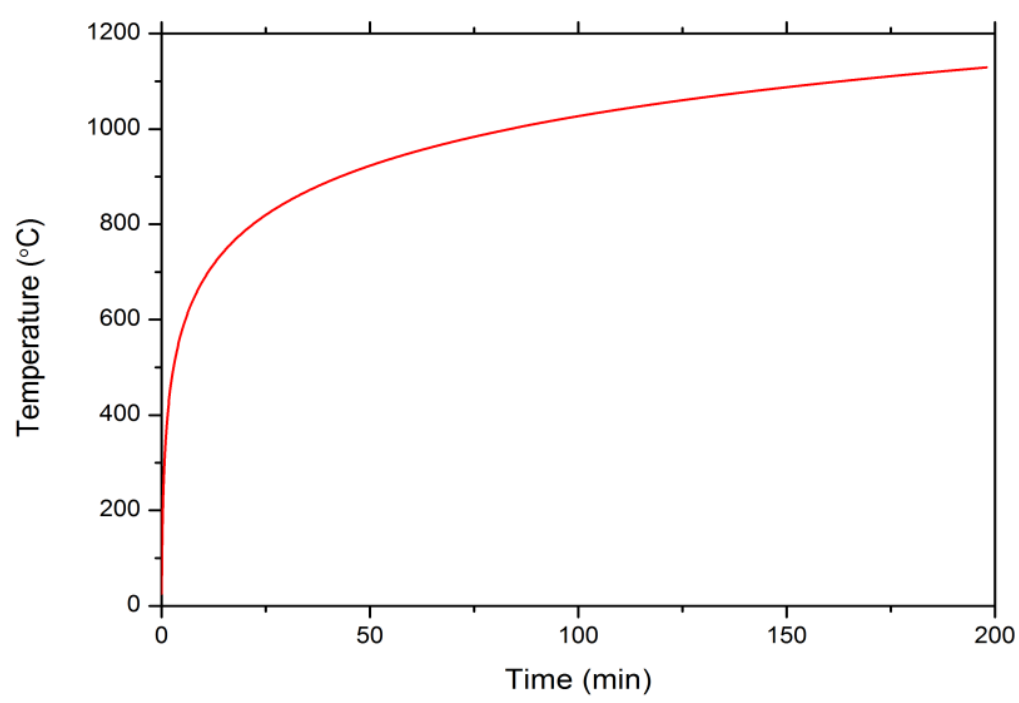

Instrumentation and Test Set-up

Type K Mineral Insulated Thermocouple Sensor with probe length and diameter of $2500 \mathrm{~mm}$ and $1.6 \mathrm{~mm}$ respectively, is adopted in this study. The cable length is $5000 \mathrm{~mm}$ and the maximum temperature that could be detected is $1300^{\circ} \mathrm{C}$. The outside and inside views of the electrical furnace for the fire test are shown in Figure 7 and 8. As shown in Figure 8, a steel cage is placed around each specimen to protect the furnace in case of vigorous spalling happens. Specimens are located at the two ends of the furnace. Thermal couples will be connected to the data logger through the openings on two sides of the furnace.

Figure 7. Outside View of Electrical Furnace



Figure 8. Inside View of Electrical Furnace 


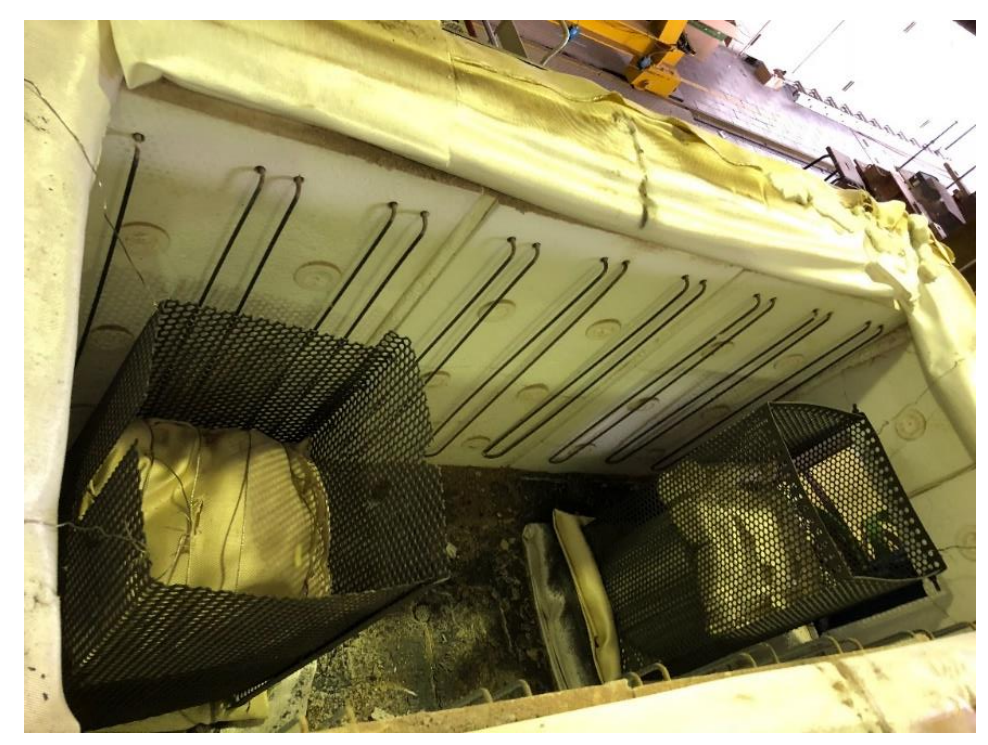

Compression Strength Test Procedures

To obtain the compressive strength of all specimens at ambient temperature and investigate the performance of the bond between HSC core and NSC outer layer of the $2 \mathrm{~L}$ specimen, compression strength tests were conducted. Dental stone was first applied to smooth the top surface of specimens, as shown in Figure 9. Since the specimens were only $300 \mathrm{~mm}$ high, a $300 \mathrm{~mm}$ long steel cube had to be placed on the compression machine to raise the specimens (Figure 10). Compressive loading was then applied to the specimen until failure.

Figure 9. Specimens Covered with Dental Stone

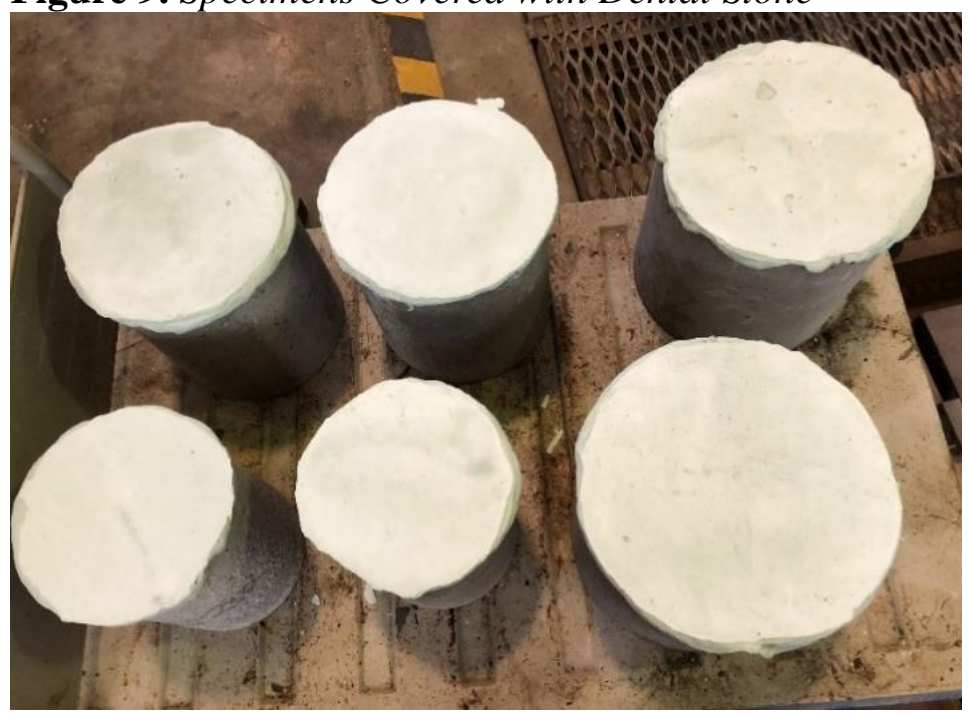


Figure 10. Steel Cube Base

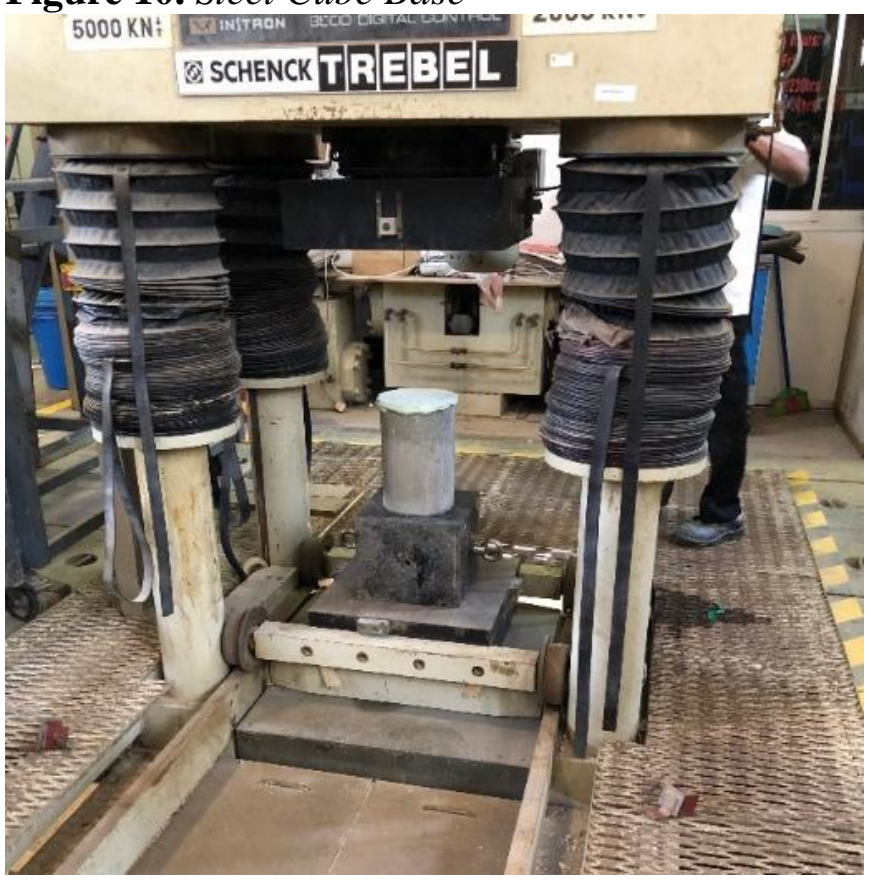

Fire Test Procedures

\section{Specimen Preparation before Heating}

First the top surface of each specimen was insulated with insulating pad made of asbestos wrapped in insulating cloth. Then the specimen was hung into the furnace using crane and placed on another insulating pad to make sure the bottom surface was also insulated. A steel cage was then added and fixed outside the specimen to protect the furnace from damage caused by the spalled concrete. The next step was to cover the top and two sides of furnace and connect thermal couples to the data logger.

\section{Determination of Heating Time}

The heating time was mainly determined by the core temperature of the specimen represented by the temperature recorded from the thermal couple located at the center. The heating criterion was that, when the core temperature reached a certain value, the furnace would be shut down immediately. Since most of the explosive spalling occurs in the temperature range of $200{ }^{\circ} \mathrm{C}$ to $400^{\circ} \mathrm{C}$ (Kanéma et al. 2011, Fu et al. 2005, Fu and Li 2011, Cheng et al. 2004, Kanema et al. 2011), $400^{\circ} \mathrm{C}$ was chosen as the threshold value to guarantee the whole specimen would be out of the suspected range of spalling, because the peripheral temperature must be higher than $400^{\circ} \mathrm{C}$ when the core temperature reaches $400^{\circ} \mathrm{C}$. Supposing that spalling does not occur by this time, we can properly assume that spalling would not occur even if the heating is continued. However, when conducting the fire test of the second pair of specimens, 
namely the $300 \mathrm{~mm}$ specimens, we found that $400^{\circ} \mathrm{C}$ as the threshold value was unrealistic because it required considerable time and effort to raise the core temperature to $400^{\circ} \mathrm{C}$. However, considering that spalling only occurs somewhat $50 \mathrm{~mm}$ from the surface of the specimen at most, it is unnecessary to heat the whole specimen over $400^{\circ} \mathrm{C}$. The threshold value for the core temperature of $250 \mathrm{~mm}$ and $300 \mathrm{~mm}$ specimens were therefore changed to $300^{\circ} \mathrm{C}$. By this time, the temperature of the outermost $50 \mathrm{~mm}$ layer would already be far higher than $400^{\circ} \mathrm{C}$. In this way, only parts that were most likely to be subjected to spalling were heated till beyond the suspected temperature.

\section{During Heating}

The specimens cannot be seen through the furnace, so the sounds throughout the heating process are recorded to indicate whether spalling has already happened.

\section{$\underline{\text { After Heating }}$}

In consideration of safety and protection of the furnace, the furnace was not opened until the gas temperature was lower than $400^{\circ} \mathrm{C}$ and based on practical experience, specimens cannot be taken out until they cooled down to lower than $100^{\circ} \mathrm{C}$.

\section{Results and Discussion}

\section{General}

The ambient compression strength test results of both specimens are presented in Table 2. Nomenclature is given by "specimen type + specimen outer diameter". For instance, 2L200 stands for the 2-layered specimen with outer diameter of $200 \mathrm{~mm}$. The column named "Calculated" is the theoretical values of failure load calculated from the strengths of HSC and NSC. The "Test" column represents the real failure loads recorded from the ambient compression tests. The final column is the ratio between the test and calculated values. By comparing the T/C ratios of $2 \mathrm{~L}$ and $\mathrm{HSC}$ specimens, it is found that the $2 \mathrm{~L}$ specimens generally have a lower ratio than $\mathrm{HSC}$, which may indicate a strength reduction for $2 \mathrm{~L}$ specimens due to the interface between HSC core and NSC outer layer. The value of T/C ratio should normally fall in the range of $0.7 \sim 1$, however, the value of 2L250 specimen is larger than 1 , which is assumed to be caused by the different strength and quality of different batches of concrete mix. Another thing to note is that no NSC outer layer fell off throughout the loading process, so it is reasonable to assume that the bond between HSC core and NSC outer layer is strong enough to withstand the loading and avoid the separation of two layers. Specimens were too brittle to 
perform residual strength test after several hours' heating. The gas temperatures inside the furnace of all three sets of fire tests are compared with the ISO834 standard curve (Figure 9). Results show that the real temperature agrees well with the target temperature for all fire tests.

Table 2. Ambient Strength Test Results

\begin{tabular}{|c|c|c|c|c|c|c|}
\hline Specimen & $\begin{array}{c}\text { Total D } \\
(\mathrm{mm})\end{array}$ & $\begin{array}{c}\text { NSC layer } \\
\mathrm{t}(\mathrm{mm})\end{array}$ & $\begin{array}{c}\text { Core } \\
\mathrm{d}\end{array}$ & $\begin{array}{c}\text { Calculated } \\
(\mathrm{km})\end{array}$ & Test $(\mathrm{kN})$ & $\begin{array}{c}\text { T/C } \\
\text { Ratio }\end{array}$ \\
\hline HSC200 & 200 & 0 & 200 & 1592.30 & 1554 & 0.98 \\
\hline 2L200 & 200 & 20 & 160 & 1390.91 & 1051 & 0.76 \\
\hline HSC250 & 250 & 0 & 250 & 2487.96 & 1934 & 0.78 \\
\hline 2L250 & 250 & 25 & 200 & 2173.30 & 2233 & 1.03 \\
\hline HSC300 & 300 & 0 & 300 & 3582.67 & 3009 & 0.84 \\
\hline 2 L300 & 300 & 30 & 240 & 3129.55 & 2304 & 0.74 \\
\hline
\end{tabular}

Figure 11. ISO834 Curve VS Real Gas Temperatures

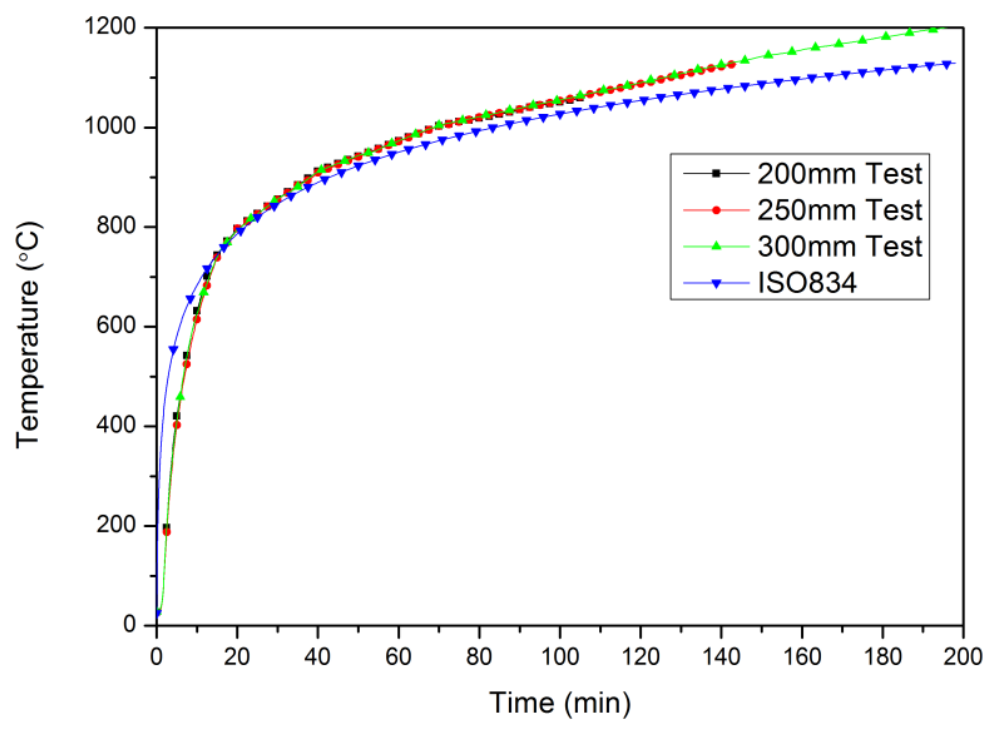

\section{Fire Test Results Analysis}

Figure 10 to 15 illustrate the comparison between real temperatures recorded from thermal couples embedded in the specimens and simulation results by ABAQUS. Real test curve is named by "Specimen type + outer diameter + thermal couple position (distance to the center of specimen)". Except from the 
center, every other position should originally have two thermal couples embedded, however, due to manufacture or heating reasons, some of the thermal couples were broken and therefore data is missing for some of the positions. The simulation curves are named by "thermal couple position + sim". For both HSC and 2L specimens, a plateau is observed generally at the temperature between $100^{\circ} \mathrm{C}$ and $150^{\circ} \mathrm{C}$, and the nearer to the center, the longer the plateau continues. This phenomenon is very likely to be caused by the evaporation and diffusion of free water in the concrete pores (Phan 2008, Lie and Celikkol 1991). When the temperature reaches around $105^{\circ} \mathrm{C}$, free water starts to evaporate and migrate towards the center of the specimen due to the pore pressure gradient. The transfer of heat in the concrete is retarded, as a result of energy being absorbed in the process of evaporation and migration, leading to a decrease in the rate of temperature rise or a nearly constant temperature period in the early stage of fire tests. The plateau ends when the concrete temperature rises to about $150^{\circ} \mathrm{C}$, by which time most of the water vapor would have escaped through the concrete surface and stop migrating. Regarding the HSC and 2L specimens with the same outer diameter, it is found that the temperatures at corresponding positions have similar values and trends, which may indicate the interface between the HSC core and NSC outer layer does not have a significant effect on the heat transfer in concrete. The NSC outer layer takes effect in preventing the heat from attacking the HSC core, which improves the performance of HSC under fire to some extent.

Figure 12. Comparison of HSC200 Specimen

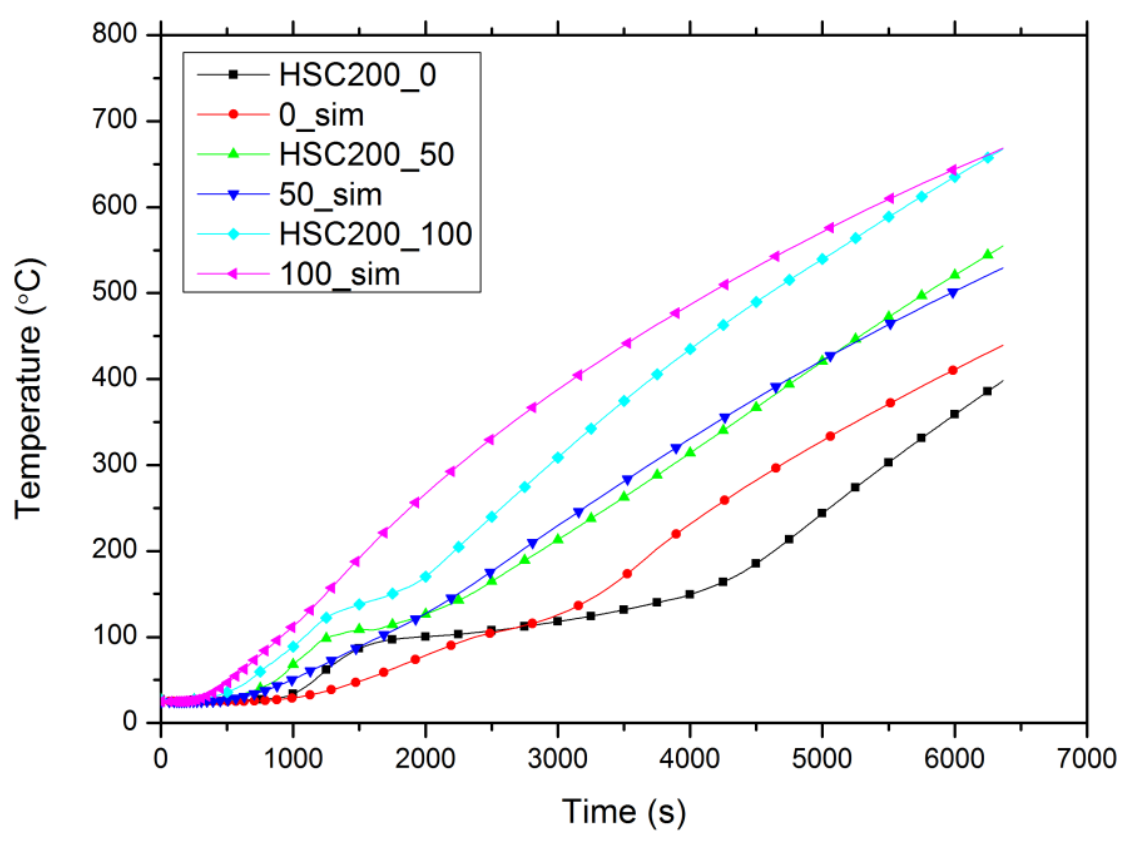


Figure 13. Comparison of 2L200 Specimen



Figure 14. Comparison of HSC250 Specimen

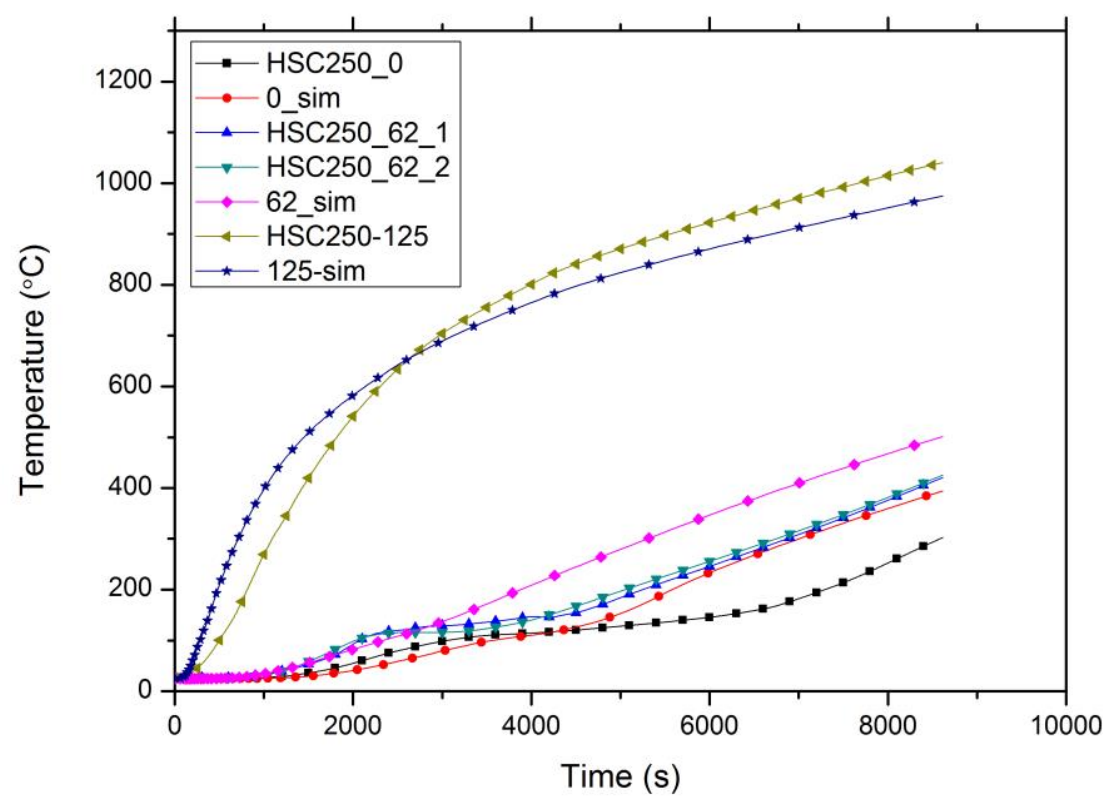


Vol. 6, No. 3

Figure 15. Comparison of 2L250 Specimen

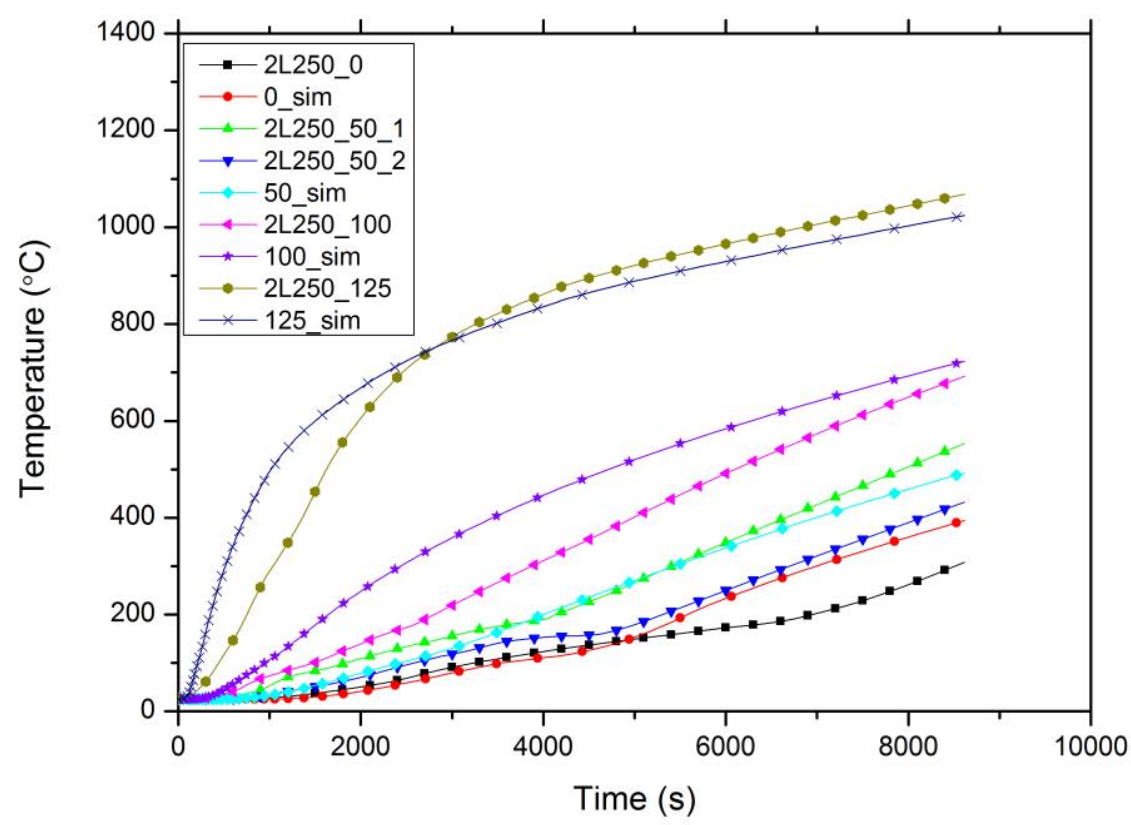

Figure 16. Comparison of HSC300 Specimen

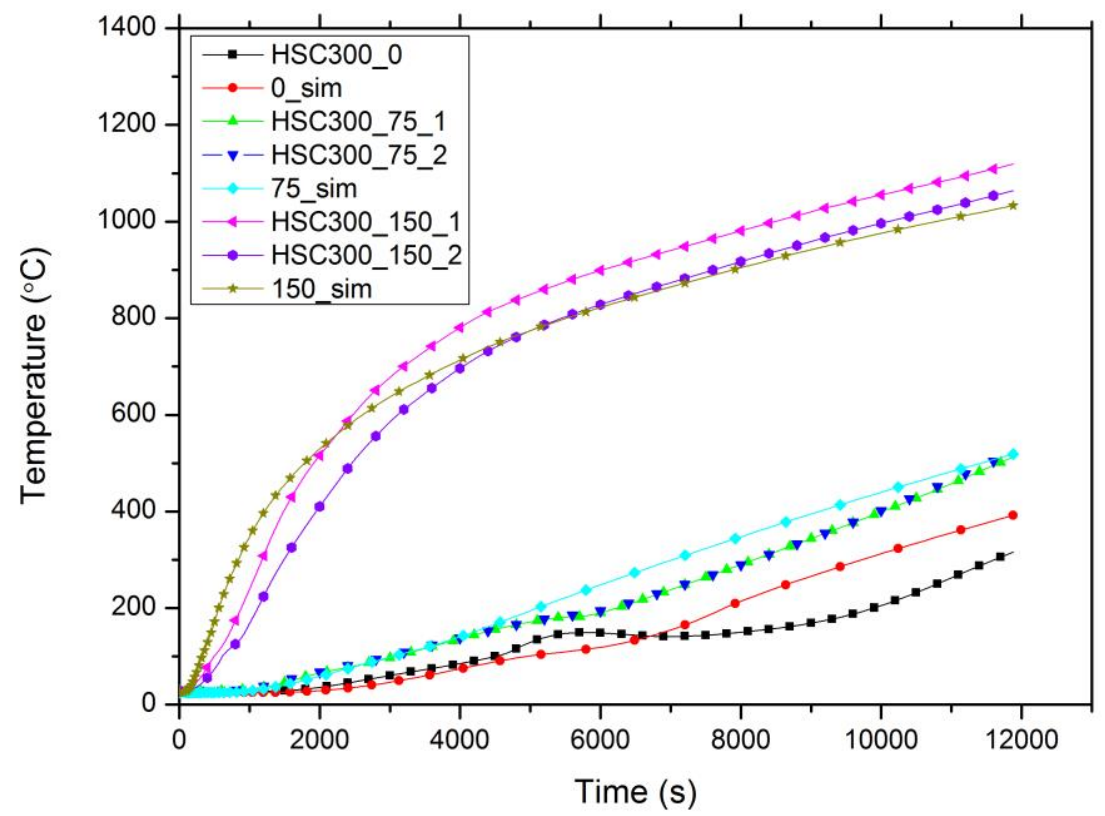


Figure 17. Comparison of 2L300 Specimen

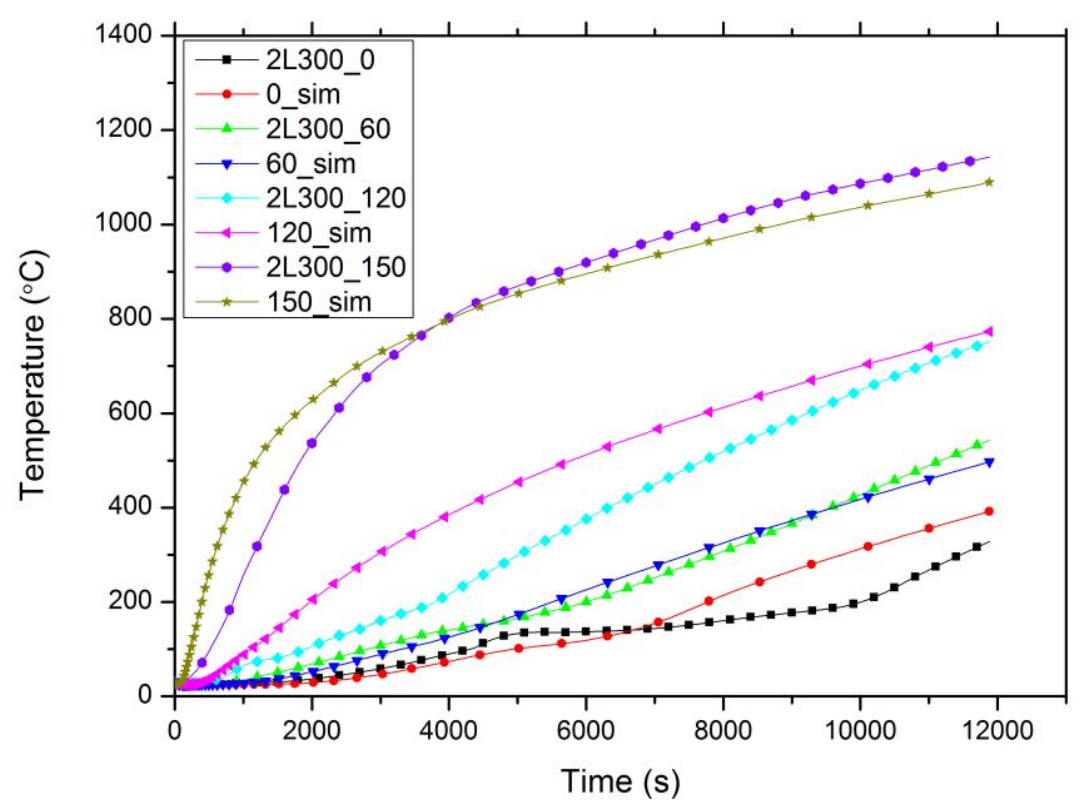

\section{Spalling Observation}

No explosive spalling was observed for all HSC and 2L specimens. The poor workmanship for casting concrete leading to the low strength and high permeability of HSC could be the main reason which prevents the happening of explosive spalling in HSC specimens. Water vapor inside the concrete was released through the pores under high temperature, pore pressure was not able to build up to exceed the tensile strength of concrete. As a result, explosive spalling was avoided for specimens. However, sounds of cracks and pops were continuously heard during the heating of HSC specimens, which may suggest the occurrence of minor spalling in the HSC specimens. NSC outer layer of $2 \mathrm{~L}$ specimens remained intact after heating, except that the outer layer of $200 \mathrm{~mm}$ specimen fell off when hanging out from furnace. The NSC layer of the $200 \mathrm{~mm} 2 \mathrm{~L}$ specimen is only $20 \mathrm{~mm}$ thick, which caused certain difficulties to the casting and manual vibration of the outer layer. Consequently, the bond between HSC and NSC is relatively weak and it is further weakened under elevated temperatures. It is deduced that the minimum thickness of NSC outer layer should be no less than $20 \mathrm{~mm}$, reasoning that once the thickness is less than $20 \mathrm{~mm}$ it would be difficult to cast and vibrate the outer layer and the bond between the two layers would become too weak. Visible cracks developed on the surface of all specimens.

\section{Post Cooling Behavior}

Post cooling spalling occurred when the $300 \mathrm{~mm}$ HSC specimen was taken 
out from furnace and cooled down in the ambient temperature. As mentioned above, thermal chemical spalling consists of sloughing-off spalling at extremely high temperature and post cooling spalling after exposing to elevated temperature (Xing et al. 2011, Annerel and Taerwe 2009). The main cause of thermal-chemical spalling is the break-down of aggregate cement bond, such as calcium silicate hydroxide and calcium hydroxide (Schneider 1988). The threshold temperature of thermal-chemical spalling is relatively high at around $750^{\circ} \mathrm{C}$. The $300 \mathrm{~mm}$ specimens were heated for the longest time at around 3.5 hours, and the core temperature would continue to rise for a period of time even the furnace is shut down. Therefore, the highest core temperature and gas temperature recorded was $713^{\circ} \mathrm{C}$ and $1213^{\circ} \mathrm{C}$ respectively, which means most part of the specimen has been heated up to over $700^{\circ} \mathrm{C}$. Thus, the occurrence of post cooling spalling can be considered reasonable.

\section{Conclusions}

The bond between the HSC core and NSC outer layer is assumed to be strong enough to withstand the loading and avoid separation of the two layers based on the ambient compression test results. However, a strength reduction may exist for the $2 \mathrm{~L}$ specimens due to the interface between the HSC core and NSC outer layer. A plateau is observed at around $100^{\circ} \mathrm{C}$ to $150^{\circ} \mathrm{C}$, which is caused by the free water evaporation and diffusion inside the concrete pores. The effect of the interface between HSC and NSC on heat transfer in concrete is not significant. And the NSC outer layer is proved to be effective in preventing the heat from attacking the HSC core. No explosive spalling was observed for all specimens. Yet sounds of cracks and pops were heard during the heating process of HSC specimens, which may indicate the occurrence of minor spalling. Post cooling spalling, whose threshold temperature is at around $750^{\circ} \mathrm{C}$, occurred when the $300 \mathrm{~mm}$ HSC specimen was taken out from furnace and cooled down in the ambient temperature. The highest core temperature and gas temperature of the $300 \mathrm{~mm}$ HSC specimen recorded was $713^{\circ} \mathrm{C}$ and $1213^{\circ} \mathrm{C}$ respectively. In practical construction projects, the thickness of NSC outer layer is recommended to be no less than $20 \mathrm{~mm}$, owing to the fact that it would be difficult to cast and vibrate the outer layer concrete and the bond between the two layers would become too weak.

\section{Acknowledgments}

The authors would like to thank Prof Tan Kang Hai and the NTU Protective Technology Research Centre for supporting the experimental tests conducted in the paper. Thanks to Research Grants Council (RGC) of Hong Kong for supporting the first author's PhD study in the University of Hong Kong. 


\section{References}

Ahmed G., Hurst J (1999) Modeling Pore Pressure, Moisture, and Temperature in High-Strength Concrete Columns Exposed to Fire. Fire Technology 35(3): 232262.

Annerel E, Taerwe L (2009) Revealing the Temperature History in Concrete after Fire Exposure by Microscopic Analysis. Cement and Concrete Research 39(12): 1239-1249.

Bažant ZP, Chern JC, Thonguthai W (1982) Finite Element Program for Moisture and Heat Transfer in Heated Concrete. Nuclear Engineering and Design 68(1): 61-70.

Castillo C, Durrani AJ (1990) Effect of Transient High Temperture on High-Strength Concrete. ACI Materials Journal 87(1): 47-53.

Chaichannawatik B, Sirisonthi A, Hussain Q, Joyklad P (2018) Mechanical Properties of Fiber Reinforced Concrete. Applied Mechanics and Materials 875: 174-178.

Cheng FP, Kodur V, Wang TC (2004) Stress-Strain Curves for High Strength Concrete at Elevated Temperatures. Journal of Materials in Civil Engineering, 16(1): 8490.

Diederichs U, Jumppanen UM, Penttala V (1988) Material Properties of High Strength Concrete at Elevated Temperatures 13.

Diederichs U, Jumppanen U, Schneider U (1995) High Temperature Properties and Spalling Behaviour of High Strength Concrete. $4^{\text {th }}$ International Workshop on High Performance Concrete-Characteristics, Material Properties and Structural Performance. Weimar, Germany.

Dwaikat MB, Kodur VKR (2009) Hydrothermal Model for Predicting Fire-Induced Spalling in Concrete Structural Systems. Fire Safety Journal 44(3): 425-434.

Felicetti R, Gambarova PG., Rosati G., Corsi F, Giannuzzi G. (1996) Residual Mechanical Properties of High-Strength Concretes Subjected to HighTemperature Cycles. $4^{\text {th }}$ International Symposium on Utilization of HighStrength/High-Prformance Concrete.

Fu Y, Wong Y, Poon C, Tang C (2005) Stress-Strain Behaviour of High-Strength Concrete at Elevated Temperatures. Magazine of Concrete Research 57(9): 535544.

Fu Y, Li L (2011) Study on Mechanism of Thermal Spalling in Concrete Exposed to Elevated Temperatures. Materials and structures, 44(1): 361-376.

Furumura F, Abe T, Shinohara Y (1995) Mechanical Properties of High Strength Concrete at High Temperatures. Proceedings of the Fourth Weimar Workshop on High Performance Concrete: Material Properties and Design. Weimar, Germany.

Gawin D, Pesavento F, Schrefler B (2003) Modelling of Hygro-Thermal Behaviour of Concrete at High Temperature with Thermo-Chemical and Mechanical Material Degradation. Computer Methods in Applied Mechanics and Engineering, 192(1314): 1731-1771.

Hammer TA (1995) High Strength Concrete Phase 3: Compressive Strength and EModulus at Elevated Temperatures. SP6 Fire Resistance, Report 6.1. SINTEF Structures and Concrete.

Hansen P, Jensen J (1995) High Strength Concrete Phase-3, Fire Resistance and Spalling Behaviour of LWA Beams. SP-6-Fire Resistance, Report 6.

Hertz K (1984) Heat-Induced Explosion of Dense Concretes. Technical University of Denmark, Institute of Building Design, No. 166.

Hertz KD (1992) Danish Investigations on Silica Fume Concretes at Elevated Temperatures. ACI Materials Journal 89(4): 345-347. 
Hertz KD (2003) Limits of Spalling of Fire-Exposed Concrete. Fire Safety Journal 38(2): 103-116.

Ichikawa Y, England G.L (2004) Prediction of Moisture Migration and Pore Pressure Build-Up in Concrete at High Temperatures. Nuclear Engineering and Design, 228(1-3): 245-259.

Jalasutram S, Sahoo DR, Matsagar V (2017) Experimental Investigation of the Mechanical Properties of Basalt Fiber-Reinforced Concrete. Structural Concrete 18(2): 292-302.

Jeongwon K, Dongwoo R, Takafumi N (2011) The Spalling Mechanism of HighStrength Concrete under Fire. Magazine of Concrete Research 63(5): 357-370.

Kalifa P, Menneteau FD, Quenard D (2000) Spalling and Pore Pressure in HPC at High Temperatures. Cement and Concrete Research 30(12): 1915-1927.

Kanéma M, Pliya P, Noumowé A, Gallias J (2011) Spalling, Thermal, and Hydrous Behavior of Ordinary and High-Strength Concrete Subjected to Elevated Temperature. Journal of Materials in Civil Engineering 23(7): 921-930.

Khaliq W, Kodur VKR (2011) Effect of High Temperature on Tensile Strength of Different Types of High-Strength Concrete. ACI Materials Journal 108(4): 394402.

Khaliq W, Kodur V (2013) Behavior of High Strength Fly Ash Concrete Columns under Fire Conditions. Materials and Structures 46(5): 857-867.

Kodur VKR (2000) Spalling in High Strength Concrete Exposed to Fire: Concerns, Causes, Critical Parameters and Cures. ASCE Structures Congress. Philadelphia, Pennsylvania, United States: American Society of Civil Engineers.

Kodur VKR, Cheng FP, Wang TC, Sultan MA (2003) Effect of Strength and Fiber Reinforcement on Fire Resistance of High-Strength Concrete Columns. Journal of Structural Engineering 129(2): 253-259.

Kodur VKR, Wang T, Cheng F (2004) Predicting the Fire Resistance Behaviour of High Strength Concrete Columns. Cement and Concrete Composites 26(2): 141153.

Lie TT, Celikkol B (1991) Method to Calculate the Fire Resistance of Circular Reinforced Concrete Columns. ACI Materials Journal 88(1): 84-91.

Lin W, Lin T, Powerscouche L (1996) Microstructures of Fire-Damaged Concrete. ACI Materials Journal 93(3): 199-205.

Mindeguia JC, Pimienta P, Noumowé A, Kanema M (2010a) Temperature, Pore Pressure and Mass Variation of Concrete Subjected to High TemperatureExperimental and Numerical Discussion on Spalling Risk. Cement and Concrete Research 40(3): 477-487.

Nassif AY, Burley E, Ridgen S (1995) A New Quantitative Method of Assessing Fire Damage to Concrete Structures. Magazine of Concrete Research 47(172): 271278.

Noumowe AN, Clastres P, Debicki G., Costaz JL (1996) Transient Heating Effect on High Strength Concrete. Nuclear Engineering and Design 166(1): 99-108.

Ozawa M, Uchida S, Kamada T, Morimoto H (2012) Study of Mechanisms of Explosive Spalling in High-Strength Concrete at High Temperatures using Acoustic Emission. Construction and Building Materials 37(Dec): 621-628.

Phan LT, Carino NJ (1998) Review of Mechanical Properties of HSC at Elevated Temperature. Journal of Materials in Civil Engineering 10(1): 58-65.

Phan LT (2002) High-Strength Concrete at High Temperature - An Overview, 501-518. Proceedings of $6^{\text {th }}$ International Symposiumon Utilization of High Strength/High Performance Concrete. Leipzig, Germany. 
Phan LT, Carino NJ (2002) Effects of Test Conditions and Mixture Proportions on Behavior of High-Strength Concrete Exposed to High Temperatures. ACI Materials Journal 99(1): 54-66.

Phan L (2008) Pore Pressure and Explosive Spalling in Concrete. Materials and Structures 41(10): 1623-1632.

Sanjayan G., Stocks LJ (1993) Spalling of High-Strength Silica Fume Concrete in Fire. ACI Materials Journal 90(2): 170-173.

Schneider U (1988) Concrete at High Temperatures-A General Review. Fire Safety Journal 13(1): 55-68.

Shirley ST, Burg RG, Fiorato AE (1988) Fire Endurance of High-Strength Concrete Slabs. Materials Journal 85(2): 102-108.

Sullivan P, Sharshar R (1992) The Performance of Concrete at Elevated Temperatures (as Measured by the Reduction in Compressive Strength). Fire Technolpgy 28(3): 240-250.

Wang J, Dai Q, Si R, Guo S (2019) Mechanical, Durability, and Microstructural Properties of Macro Synthetic Polypropylene (PP) Fiber-Reinforced Rubber Concrete. Journal of Cleaner Production 234(Oct): 1351-1364.

Xing Z, Beaucour AL, Hebert R, Noumowe A, Ledesert B (2011) Influence of the Nature of Aggregates on the Behaviour of Concrete subjected to Elevated Temperature. Cement and Concrete Research 41(4): 392-402.

Zdeněk PB, Werapol T (1979) Pore Pressure in Heated Concrete Walls: Theoretical Prediction. Magazine of Concrete Research 31(107): 67-76.

Zheng Y, Wu X, He G., Shang Q, Xu J, Sun Y (2018) Mechanical Properties of Steel Fiber-Reinforced Concrete by Vibratory Mixing Technology. Advances in Civil Engineering 2018. https://doi.org/10.1155/2018/9025715. 
